\title{
Polimorfismo Químico: Panorama Legislacional e Aplicação Farmacêutica
}

\author{
Marina Teodoro, Jean M. F. Custodio \& Hamilton B. Napolitano
}

O mercado brasileiro de medicamentos é regulamentado pela Agência Nacional de Vigilância Sanitária (ANVISA), que normatiza e controla a fabricação, distribuição e comercialização de remédios em todo o território nacional. Além disso, a ANVISA teve que estabelecer normas para as leis de genéricos e patentes coexistirem de forma que, após passada fase de validade das patentes, outras empresas possam criar genéricos de igual qualidade ao medicamento de referência. Nesse cenário, destacam-se os polimorfos, que são diferentes formas cristalinas de um mesmo composto molecular, sendo os fármacos mais abordados quando considerada a regulamentação abordada pela ANVISA. Esse artigo tem como objetivo a apresentação de todos os parâmetros legais envolvidos na produção e comercialização de polimorfos e genéricos e fármacos e, a fim de exemplificação, serão apresentados os principais polimorfos do fármaco comercializado diclofenaco.

Palavras-chave: Patentes; Polimorfismo; Genéricos.

The Brazilian market for medicines is regulated by the Agência Nacional de Vigilância Sanitária (ANVISA), which regulates and controls the manufacture, distribution and sale of medicines throughout the country. In addition, ANVISA had to establish standards for generic and patent laws to coexist so that, after the patent validity phase, other companies could create generics of the same quality as the reference drug. Thus, we highlight the polymorphs, which are different crystalline forms of the same molecular compound, being the drugs most approached when considering the regulation addressed by ANVISA. This article aims to present all the legal parameters involved in the production and commercialization of polymorphs and generics and drugs and, for exemplification, the main polymorphs of the drug marketed diclofenac will be presented.

Keywords: Patents; Polymorphism; Generic. 


\section{Introdução}

A edição da legislação que regulamentou a fabricação e venda de medicamentos genéricos foi um avanço social para o Brasil. Ao permitir a utilização da fórmula de medicamentos de referência para a fabricação de produtos de qualidade e baixo custo, o Estado propiciou à população acesso a tratamentos anteriormente impraticáveis pelo custo.

Por outro lado, o legislador protegeu o produtor de inovações farmacêuticas, ao conceder, por meio da lei de patentes e por um determinado período, a exclusividade da comercialização da invenção. Essa situação trouxe dificuldades iniciais quanto à formulação dos produtos, uma vez que muitos detentores de patentes dificultaram a passagem de formulação correta dos medicamentos de referência, objetivando embaraçar a entrada de concorrentes genéricos no mercado. Essa realidade foi corrigida pelos órgãos de controle e regulação, com o estabelecimento de critérios bem definidos para as pesquisas e divulgação de resultados, inclusive com a padronização de variáveis.

\section{Legislação Federal Sobre Patentes/Genéricos}

A propriedade intelectual é o conjunto de direitos que assiste uma determinada pessoa, empresa ou entidade por conta de sua atividade criativa. Pode dizer respeito a produções artísticas, literárias e cientificas, abrangendo invenções, desenhos industriais, programas de computador, ou qualquer coisa produzida pela inteligência humana. A grosso modo, há duas categorias distintas: direitos de autor e propriedade industrial, nas quais estão inseridas as patentes. As patentes são uma vantagem concedida pelo Estado a fim de se bonificar o esforço para chegar a invenção de algo novo, que tenha aplicabilidade industrial. Como contrapartida o detentor da patente deve tornar público o conhecimento básico que define a sua novidade a fim de que sirva de colaboração para futuras inovações.

No Brasil, o processo de registro de patentes é feito junto ao Instituto Nacional de Propriedade Intelectual
(INPI), segundo determinação expressa da Lei $\mathrm{n}^{\circ} 9.279$, de 14 de maio de 1996. Na mesma lei, o art. 229C prevê que os produtos farmacêuticos deverão ter prévia anuência da Agência Nacional de Vigilância Sanitária (ANVISA) para comercialização. Nota-se que se trata de bem engendrada burocracia a fim de barrar a entrada no mercado de produtos que não tenham sido suficientemente testados e aprovados por rígidos sistemas de controle.

A ANVISA define o medicamento como sendo "um produto farmacêutico, tecnicamente obtido ou elaborado, com finalidade profilática, curativa, paliativa ou para fins de diagnóstico" (ANVISA, 2009). A lei no 9.787, de 10 de fevereiro de 1999, estabelece a existência de três modalidades de medicamentos: os de referência, os genéricos e os similares. Os de referência são os produtos inovadores, criados partir de novas substâncias produzidas em laboratório e aprovados pelos órgãos de registro federal para serem comercializados.

O medicamento genérico é o que contêm o mesmo princípio ativo, dose e propriedades do medicamento de referência. Ele somente passa a ser produzido após findo o prazo de vencimento de proteção da patente do produto de referência. Os genéricos são remédios similares aos medicamentos de referência (BRASIL, 1999).

\section{Polimorfismo e Patentes}

Polimorfismo é a habilidade de uma substância existir no estado sólido com, no mínimo, duas estruturas cristalinas diferentes, rearranjando seus átomos. Por consequência, cada polimorfo é uma fase cristalina distinta (Haleblian \& Mccrone, 1969). Apresentam diferenças físico-químicas embora tendam a uma mesma finalidade. Como a definição do que é polimorfo é ambígua e sujeita a entendimentos diversos, o polimorfismo de medicamentos gera controvérsias quando se interpreta o conteúdo de uma patente, o que é utilizado como estratégia pelos detentores de patentes para impedir e retardar a entrada de concorrentes genéricos no mercado.

Trata-se, portanto, de fenômeno impactante para a indústria farmacêutica por influenciar diretamente a 
qualidade dos medicamentos, sobretudo dos genéricos. As agências reguladoras têm atuado de forma a minimizar os riscos à população, exigindo, para o registro de medicamentos de fármacos novos ou genéricos, estudos que comprovem o monitoramento e o controle de qualidade das formas cristalinas existentes.

No Brasil, a ANVISA exige para o registro de medicamentos genéricos, similares ou inovadores informações detalhadas sobre os prováveis polimorfos e, necessariamente a metodologia analítica para a sua determinação (Brasil, 2003a, 2003b) tanto na matériaprima como no produto. Como a legislação permite o registro de até três fabricantes do princípio ativo para cada medicamento, é feita uma avaliação técnica criteriosa, tanto pelo laboratório fabricante como pela agência reguladora, sobre possíveis diferenças na matéria-prima adquirida e dos impactos relacionados ao polimorfismo.

\section{Regulamentação da Anvisa Sobre o Assunto}

No âmbito da ANVISA são editadas RDCs - Resoluções Da Diretoria Colegiada, que são normatizações sobre vários tipos de produtos. No caso específico dos polimorfos, nos interessam as RDCs 166 e 167.

Ambas dispõem sobre a validação de métodos analíticos, isto é, trazem os métodos analíticos empregados em insumos farmacêuticos, medicamentos e produtos biológicos em todas as suas fases de produção. Com essas resoluções a ANVISA estabelece que "os métodos analíticos aplicados aos produtos sob investigação utilizados em ensaios clínicos devem ter sua adequabilidade demonstrada de acordo com [as normas da resolução]" e qualquer abordagem diferente deve ser justificada. Mais especialmente, a resolução exige que os dados relevantes obtidos durante a condução da validação analítica, e as fórmulas utilizadas para cálculo sejam protocoladas junto com a petição de interesse ante a ANVISA, o que implica na transparência quanto à metodologia de validação e ocorrência de polimorfismo em fármacos.

Essa padronização é de suma importância sobretudo para o mercado dos genéricos. Diante de estudos bem delimitados e de resultados que seguem as determinações da ANVISA, uma empresa que deseje desenvolver um medicamento genérico tem diretrizes para criação de fármacos seguros, já que estará seguindo a formulação adequada.

\section{Medicamentos Genéricos}

A promulgação da lei 9.787/99 - lei de genéricos foi o resultado de ações do Ministério da Saúde e da, então recém-criada, Agência Nacional de Vigilância Sanitária (ANVISA) para aumentar o acesso da população ao tratamento medicamentoso e reduzir o preço dos medicamentos (BRASIL, 1999a). A lei no 9.787 estabeleceu normas técnicas para o registro de medicamentos, baseandose em normas já existentes em países como Estados Unidos, Canadá e pela Comunidade Europeia (ARAÚJO, 2010).

Objetivando a redução dos custos com saúde no país, a lei dos genéricos determinou que a aquisição de medicamentos e até mesmo as prescrições médicas, no Sistema Único de Saúde (SUS), passassem a ser feitas usando a denominação do princípio ativo. Também nas compras públicas se prevê a compra preferencial de genéricos, quando o preço e demais condições forem favoráveis.

\section{Aplicação Farmacêutica: Diclofenaco}

O diclofenaco é um fármaco anti-inflamatório não esteroide (AINE) que possui boa ação analgésica. Dentre os nomes comercialmente conhecidos, destacam-se: Cambia ${ }^{\circledR}$, Cataflam ${ }^{\circledR}$, Diclac $\AA$, Diclo $P \AA$, Voltaren ${ }^{\circledR}$, Zorvolex ${ }^{\circledR}$ e Zipsor ${ }^{\circledR}$. A fim de analisar os polimorfos conhecidos desse fármaco, foi feita uma busca no Cambridge Crystallographic Data Centre (CCDC) e os dados encontrados foram comparados entre si.

Embora a busca no CCDC tenha retornado 11 diferentes depósitos para o diclofenaco, verificou-se que tais depósitos estão distribuídos em quatro polimorfos de código SIKLIH, SIKLIH2, SIKLIH4 e SIKLIH5. Desses 4 polimorfos, dois 
são do sistema cristalino monoclínico e grupo espacial C2/c e apresentam métricas a $=20,278$ e 20,291 $\AA ; \mathrm{b}=6,987$ e $6,995 \AA ; c=23,265$ e $20,114 \AA ; \alpha=\gamma=90^{\circ}$ e $\beta=125,64^{\circ}$ e $109,66^{\circ}$ para SIKLIH e SKILIH5, respectivamente. Um terceiro polimorfo, o SIKLIH, também pertence ao sistema monoclínico, mas possui grupo espacial $\mathrm{P} 21$ /c, com métricas $\mathrm{a}=8,384 \AA ; \mathrm{b}=10,898 \AA ; \mathrm{c}=14,882 \AA ; \alpha=\gamma=90^{\circ}$ e $\beta=92,76^{\circ}$. Por fim, o último polimorfo encontrado tem código SIKLIH4 e cristalizou-se sob o sistema cristalino ortorrômbico e grupo espacial Pcan. Sua cela unitária tem dimensões $\mathrm{a}=7,082 \AA ; \mathrm{b}=17,256 \AA ; \mathrm{c}=23,607 \AA ; \alpha=$ $\beta=\gamma=90^{\circ}$. A seguir, são apresentadas as representações ORTEP de todos os polimorfos:

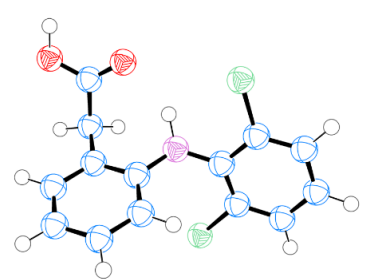

(a)

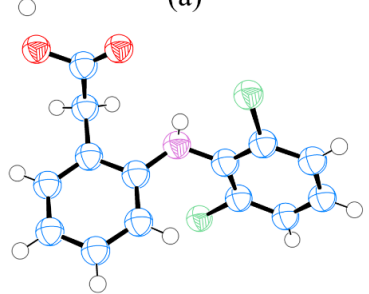

(c)

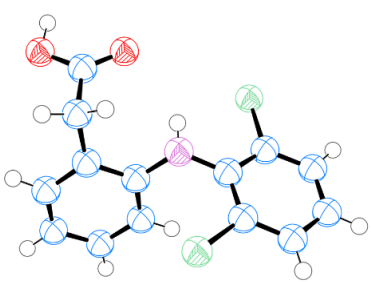

(b)

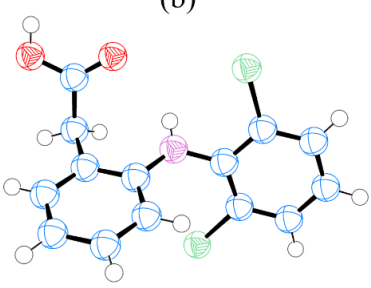

(d)
Figura 1. Representações ORTEP dos polimorfos SIKLIH (a), SIKLIH2 (b), SIKLIH4 (c) e SIKLIH5 (d) com elipsoides a $60 \%$ de probabilidade. Hidrogênios são representados como esferas de raio arbitrário.

Embora os polimorfos sejam visualmente semelhantes, mudanças sutis em suas conformações podem afetar seu desempenho farmacológico, no que diz respeito desde a estabilidade quanto ao reconhecimento molecular em biomoléculas. Tomando como ponto de referência o anel aromático não-clorado, a principal diferença conformacional nos polimorfos se dá pela configuração dos ligantes carboxila, do hidrogênio da amina e do anel clorado. Os polimorfos SKILIH, SKILIH4 e SKILIH5 adotam uma conformação na qual o grupo carboxila e o hidrogênio encontram-se projetados para fora do plano e o aromático clorado tem uma rotação anti-horária. Tal configuração é invertida para SKILIH2. Todos os polimorfos monoclínicos são estabilizados por ligações de hidrogênio fortes intramoleculares (envolvendo o hidrogênio da amina e a carbonila) e intermoleculares com um arranjo esperado para ácidos carboxílicos. Em contrapartida, devido à conformação do único polimorfo ortorrômbico, o mesmo apresenta apenas uma ligação de hidrogênio, o que pode resultar em uma menor estabilidade. A Figura 2 sumariza os empacotamentos cristalinos dos polimorfos encontrados para o diclofenaco, evidenciando as diferenças em seus arranjos supramoleculares.

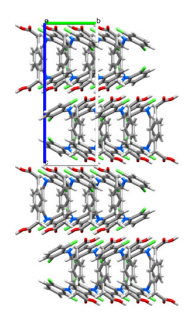

(a)

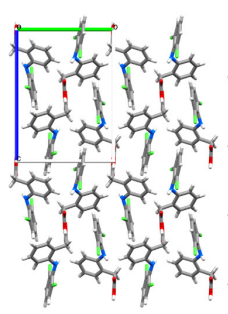

(b)

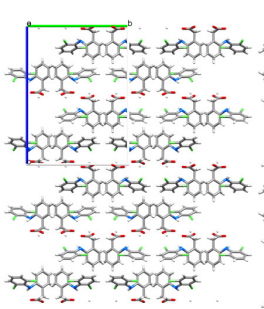

(c)

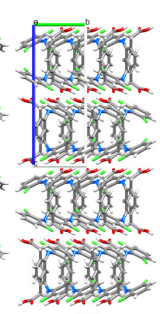

(d)
Figura 2. Empacotamentos cristalinos de SIKLIH (a), SIKLIH2 (b), SIKLIH4 (c), e SIKLIH5 (d)

\section{Conclusão}

A edição da lei dos genéricos ampliou o acesso da população aos medicamentos, representando verdadeiro avanço social. A criação de órgãos de regulação como a ANVISA, que passaram a controlar de forma mais rigorosa e com critérios técnicos bem definidos o desenvolvimento e fabricação de remédios, é um dos fatores que contribuíram para o sucesso dessa empreitada. Dentro desse contexto, a própria indústria farmacêutica modificou suas práticas, atuando de forma mais objetiva na questão das patentes e possibilitando a diminuição de preços com os remédios similares. A apresentação dos principais polimorfos do 
fármaco diclofenaco, amplamente comercializado devido à sua ação anti-inflamatória, corroborou a importância de toda a regulamentação legal apresentação para os polimorfos e genéricos.

\section{Referências}

1. Araújo, L. U.; Albuquerque, K. T.; Kato, K. C.; Silveira, G. S.; Maciel, N. R.; Spósito, P. A.; Barcellos, N. M. S.; Souza, J.; Bueno, M.; Storpirtis, S. Medicamentos genéricos no Brasil: panorama histórico e legislação. Rev. Pan. de Salud Publica. Ouro Preto, v. 28, n. 6 , p. 480-492; 2010.

2. Brasil, Agência Nacional de Vigilância Sanitária - ANVISA. Medicamentos Genéricos: oriente-se. Cartilha. Brasília, DF. 1999a.

3. , Lei $\mathrm{n}^{\mathrm{o}}, 9.787$, de 10 de fevereiro de 1999. Altera a Lei $\mathrm{n}^{\circ} 6.360$, de 23 de setembro de 1976, que dispõe sobre a vigilância sanitária, estabelece o medicamento genérico, dispõe sobre a utilização de nomes genéricos em produtos farmacêuticos e dá outras providências. Diário Oficial da União. Brasília, DF. 10 fev. 1999.

4. Diclofenac. MedlinePlus. Disponível em: https://medlineplus.gov/ druginfo/meds/a689002.html acesso em 19 de março de 2018

5. Haleblian J. Characterization of habits and crystalline modification of solids and their pharmaceutical applications. J Pharm Sci. 1975;64(8):1269-88.

\section{Marina Teodoro ${ }^{*}$, Jean $M$. F. Custodio 2 \& Hamilton B. Napolitano'}

\footnotetext{
${ }^{1}$ Centro Universitário de Anápolis, Anápolis-GO, Brasil

${ }^{2}$ Universidade Federal de Goiás, Goiânia-GO, Brasil

*E-mail: marinastj@gmail.com
} 